\title{
MIEDZYNARODOWE CZY KRAJOWE? ANALIZA BIBLIOMETRYCZNA POLSKICH CZASOPISM PEDAGOGICZNYCH
}

Streszczenie: W artykule przedstawiono analizę umiędzynarodowienia 73 polskich czasopism reprezentujących dyscyplinę pedagogiki. Analizowane parametry umiędzynarodowienia dotyczyły: języka publikacji, afiliacji redaktorów i członków rad naukowych oraz autorów. Nie uwzględniono analizy afiliacji recenzentów ze względu na różne praktyki redakcji w umieszczaniu informacji w tym zakresie i w związku z tym brakiem reprezentatywnej próby czasopism. Źródłem danych były strony internetowe czasopism i zawartość numerów opublikowanych w 2019 roku. W wyniku badania ustalono, że niewielka liczba polskich czasopism pedagogicznych posiadała wysokie wartości wybranych parametrów umiędzynarodowienia: 17 czasopism wyłącznie angielskojęzycznych (23 proc.), dziewięć czasopism z wysokim odsetkiem redaktorów i członków rad naukowych spoza Polski (12 proc.), pięć czasopism z wysokim odsetkiem autorów spoza Polski (7 proc.). Współpraca z redaktorami i członkami rad naukowych oraz autorami spoza Europy była na niskim poziomie. Na podstawie analizy nakreślono możliwe (międzynarodowe i krajowe) kierunki rozwoju polskich czasopism pedagogicznych. Przygotowano również rekomendacje o charakterze formalnym dla redaktorów i wydawców tych czasopism.

Słowa kluczowe: polskie czasopisma pedagogiczne, umiędzynarodowienie, redaktorzy, członkowie rad naukowych, autorzy publikacji, język publikacji

* Dr Aneta Drabek, Biblioteka Uniwersytetu Śląskiego w Katowicach; e-mail: aneta.drabek@ ciniba.edu.pl.

** Dr Magdalena Bemke-Świtilnik, Główny Instytut Górnictwa w Katowicach; e-mail: mbemke@ gig.eu. 


\section{Wprowadzenie}

Nauka zawsze miała wymiar globalny. Obieg idei, problemów badawczych i metod ich rozwiązywania nie był bowiem zamknięty w obrębie jednej lokalnej społeczności. Należy jednak zauważyć, że tempo ponadnarodowej komunikacji naukowej znacznie zwiększyło się wskutek rozwoju nowych technologii. Wykorzystywane kanały komunikacji, w tym czasopisma, często nie ograniczają się już do środowisk lokalnych i krajowych. Wiąże się to $\mathrm{z}$ umiędzynarodowieniem czasopism, które są tworzone przez redaktorów i członków rad naukowych z różnych krajów. Manuskrypty autorów $z$ różnych stron świata są oceniane przez międzynarodowe grona ekspertów, a zawartość periodyków jest udostępniania globalnej społeczności na stronach internetowych i w bazach danych. Umiędzynarodowienie czasopism ma na celu nie tylko poszerzenie kręgu odbiorców o autorów i czytelników zagranicznych, lecz także stworzenie miejsca publikacji dla autorów krajowych, którzy muszą przygotować swoje teksty w języku innym niż narodowy, co może być dla nich pierwszym etapem do publikowania w periodykach zagranicznych (Kulczycki, Rozkosz, Drabek 2019). Umiędzynarodowienie czasopism naukowych jest tematem często podejmowanym przez badaczy. Przez wiele lat przedmiotem badań były najbardziej prestiżowe periodyki zdominowane przez redaktorów, rady naukowe i autorów ze Stanów Zjednoczonych Ameryki Północnej. Chociaż wspomniany temat jest wciąż aktualny (zob. König 2019), można jednak zaobserwować dużą liczbę analiz dotyczących umiędzynarodowienia czasopism wydawanych w krajach peryferyjnych i półperyferyjnych, które nie zajmują najwyższych miejsc w światowych rankingach (np. Fradkin 2017).

Chociaż umiędzynarodowienia nie należy utożsamiać $\mathrm{z}$ jakością, jednak jest ono jednym z elementów definiujących czasopisma prestiżowe. Kryteria umiędzynarodowienia są brane pod uwagę w ocenie czasopism aplikujących do baz danych czy tworzenia rankingów. W Polsce od ponad 20 lat czasopisma są ewaluowane na potrzeby polityki naukowej państwa. W ewaluacji wykorzystuje się różne kryteria, $\mathrm{w}$ tym bibliometryczne, formalne i merytoryczne. Umiędzynarodowienie polskich czasopism naukowych było częścią oceny czasopism, przeprowadzonej na zlecenie Ministerstwa Nauki i Szkolnictwa Wyższego w latach 2012-2015, i przez to stało się elementem kształtującym polityki redakcyjne wielu polskich periodyków. Jak wykazały badania, część czasopism dokonała pozornego umiędzynarodowienia, zmieniając proporcje między liczbą członków Rady Naukowej z Polski i z zagranicy, a także zwiększając (przynajmniej deklaratywnie) liczbę zagranicznych recenzentów, natomiast liczba artykułów w językach innych niż polski oraz autorów spoza Polski nie zmieniła się znacząco (Kulczycki, Rozkosz, Drabek 2019). Jednakże niektóre redakcje i wydawcy czasopism potraktowali te kryteria jako ważne wskazówki wyznaczające kierunek rozwoju, co w kolejnych latach przełożyło się choćby na zwiększenie liczby periodyków indeksowanych w międzynarodowych bazach 
danych, np. połowa polskich czasopism humanistycznych rejestrowanych w bazie Scopus została dodana po 2013 roku (Drabek, Bemke-Świtilnik 2020b).

Badania dotyczące czasopism pedagogicznych koncentrują się na analizie ich zawartości, celem ustalenia najczęściej podejmowanych tematów i stosowanej metodologii badań pedagogicznych (Yalcin, Yavuz, Dibek 2015), wybranych metod badań (Lopez-Fernandez, Molina-Azorín 2011; Pasikowski 2018). Podejmowana jest również tematyka umiędzynarodowienia tych czasopism. Analizę umiędzynarodowienia $\mathrm{z}$ wykorzystaniem metod bibliometrycznych, $\mathrm{w}$ tym analizy cytowań, przeprowadzono dla czasopism brazylijskich indeksowanych w bazie Scopus (Martín, Jimenez-Fanjul, Leon-Mantero, Maz-Machado 2018). Wykonano również analizę pięciu czasopism pedagogicznych indeksowanych w Web of Science Core Collection, rozpatrując możliwą stronniczość recenzentów i redaktorów tych czasopism i jej wpływ na niskie umiędzynarodowienie analizowanych periodyków (Cheung 2009).

W ramach dociekań dotyczących polskiego czasopiśmiennictwa Piotr Kowolik (1999) przedstawił definicje czasopism pedagogicznych, ich cele i zadania, funkcje i klasyfikację. Autor omówił krótko siedem etapów rozwoju polskiego czasopiśmiennictwa pedagogicznego po II wojnie światowej. Analizę zakończył na latach 9o. XX wieku, podkreślając, iż liczba czasopism pedagogicznych zmalała po 1989 roku (Kowolik 1999). Ewa Rozkosz (2017) zajęła się polskimi czasopismami pedagogicznymi umieszczonymi w wykazach czasopism punktowanych w latach 2012, 2013 i 2015. Autorka za pomocą metod statystycznych przeanalizowała parametry umiędzynarodowienia tych czasopism, których wartości były deklarowane przez przedstawicieli redakcji w ramach ankiety ewaluacyjnej prowadzonej przez Ministerstwo Nauki i Szkolnictwa Wyższego. Niniejszy artykuł jest niejako kontynuacją podjętego wcześniej wątku umiędzynarodowienia polskich czasopism pedagogicznych. Jednak różni się on pod względem materiału badawczego w postaci czasopism wybranych do badań (inna klasyfikacja nauk) i danych, zaczerpniętych bezpośrednio $\mathrm{z}$ analizowanych czasopism $\mathrm{i}$ ich stron internetowych.

$\mathrm{W}$ ramach przedstawionego badania przeanalizowano wybrane elementy umiędzynarodowienia polskich czasopism pedagogicznych (język publikacji, afiliacje redaktorów i członków rad naukowych, a także autorów) celem przedstawienia ich stanu obecnego i podjęcia na tej podstawie próby nakreślenia kierunków ich rozwoju.

\section{Materiały i metody}

Niniejszej analizie zostały poddane polskie czasopisma, które w wykazie czasopism naukowych (Komunikat Ministra Nauki i Szkolnictwa Wyższego z dnia 18 grudnia 2019 r. w sprawie wykazu czasopism naukowych i recenzowanych materiałów 
$z$ konferencji międzynarodowych, 2019) mają przyporządkowaną dyscyplinę pedagogika ${ }^{1}$. W wykazie można znaleźć 1436 czasopism z pedagogiki, w tym 78 periodyków polskich. Wykaz czasopism naukowych i recenzowanych materiałów $z$ konferencji międzynarodowych wraz z przypisana liczba punktów $z 18$ grudnia 2019 roku (Komunikat..., 2019) składa się z 29418 tytułów czasopism wraz z przypisaną im punktacją (od 20 do 200 pkt) oraz dyscypliną lub dyscyplinami, zgodnie z klasyfikacją nauk zamieszczoną w Rozporzadzeniu Ministra Nauki i Szkolnictwa Wyższego $z$ dnia 20 września 2018 roku w sprawie dziedzin nauki i dyscyplin naukowych oraz dyscyplin artystycznych (Rozporzadzenie..., 2018a). Wspomniany akt prawny wprowadził od 1 października 2018 roku nową klasyfikację w zakresie dziedzin nauki i dyscyplin naukowych oraz dyscyplin artystycznych, która od tej pory ma wpływ na bieżącą działalność naukową w Polsce, jak również na planowaną w 2022 roku ewaluację jakości działalności naukowej. Ponieważ ewaluacja będzie przeprowadzana w ramach poszczególnych dyscyplin naukowych, konieczne okazało się ich przyporządkowanie do czasopism w wykazie. Klasyfikacja składa się z ośmiu dziedzin i 47 dyscyplin. Pedagogika jest jedną z 11 dyscyplin w ramach dziedziny nauk społecznych. Wspomniany wykaz czasopism został przygotowany według nowo opracowanych kryteriów. Podstawą do jego skonstruowania stały się wszystkie czasopisma obecnie indeksowane w dwóch największych międzynarodowych bazach danych (Scopus oraz Web of Science Core Collection) oraz tytuły wybrane przez ekspertów z ERIH Plus. Dodano również 500 tytułów polskich czasopism wyłonionych w konkursie „Wsparcie dla czasopism naukowych”. Punktacja dla czasopism zależała od wskaźników bibliometrycznych oraz od opinii zespołów eksperckich i Komisji Ewaluacji Nauki.

Analizą objęto 73 z 78 czasopism reprezentujących dyscyplinę pedagogiki. Pełny wykaz znajduje się w Załączniku 1. Wykluczone zostały te tytuły, które w czasie gromadzenia danych (grudzień 2020 roku) nie miały opublikowanego kompletnego rocznika 2019 (dwa periodyki) lub na stronie internetowej czasopisma nie były dostępne pełne teksty wszystkich artykułów z 2019 roku (jeden tytuł), a także dwa czasopisma jedynie współwydawane przez polskie instytucje.

Do badania wykorzystano informacje dotyczące składu redakcji, rady naukowej oraz recenzentów, umieszczone na stronach WWW czasopism, a także informacje o afiliacji autorów artykułów opublikowanych w 2019 roku (pominięte zostały recenzje, komunikaty, sprawozdania oraz noty redakcyjne). Liczba autorów i krajów

1 Dziewiątego lutego 2021 roku został opublikowany Komunikat Ministra Edukacji i Nauki w sprawie wykazu czasopism naukowych i recenzowanych materiałów z konferencji międzynarodowych, który wraz z Komunikatem $z 18$ lutego 2021 roku o zmianie i sprostowaniu komunikatu w sprawie wykazu czasopism naukowych i recenzowanych materiałów $z$ konferencji międzynarodowych ustanowił nowy wykaz czasopism punktowanych. Wykaz z 2021 roku poszerzył liczbę punktowanych czasopism z pedagogiki do 1722 tytułów, w tym 17 polskich czasopism, nie uwzględnionych w wykazie ogłoszonym w 2019 roku. Niniejszy artykuł opiera się na danych zgromadzonych w grudniu 2020 roku. 
afiliujących uwzględniała każdą $\mathrm{z}$ osób tyle razy, ile razy pojawiała się $\mathrm{w}$ zespole autorów (np. jeśli ten sam badacz opublikował w 2019 roku dwa artykuły, był uwzględniany dwukrotnie). W przygotowaniu analizy wykorzystano następujące źródła danych:

- strona WWW czasopisma (jeśli czasopismo miało więcej niż jedną stronę, wybrano tę aktualną lub zawierającą więcej informacji),

- baza Arianta - naukowe i branżowe polskie czasopisma elektroniczne (autorzy bazy: Aneta Drabek, Arkadiusz Pulikowski),

- CEEOL - Central and Eastern European Online Library - baza została wykorzystana $\mathrm{w}$ dwóch przypadkach, gdy pobranie pełnych tekstów ze strony nie było możliwe.

\section{Ogólna charakterystyka polskich czasopism pedagogicznych}

Spośród badanych czasopism, 29 reprezentowało tylko jedną dyscyplinę (pedagogikę). Pozostałe 44 czasopisma miały charakter interdyscyplinarny i publikowały prace $\mathrm{z}$ więcej niż jednej dyscypliny, a często także z więcej niż jednej dziedziny (od jednej do czterech). Najwięcej dyscyplin (10) przyporządkowano czasopismu "Siedleckie Zeszyty Komeniologiczne. Seria Pedagogika”.

Znacznej większości czasopism przypisano najmniejszą możliwą liczbę punktów na wykazie czasopism punktowanych (20 pkt). Jedynie trzy czasopisma („Studia Socjologiczne”, „Przegląd Badań Edukacyjnych” i „Resocjalizacja Polska”) miały przypisaną liczbę 70 punktów, a dwa kolejne - 40 punktów („Qualitative Sociology Review”, „Images. The International Journal of European Film, Performing Arts and Audiovisual Communication"). Wśród 73 czasopism, 61 było obecnych w wykazie czasopism punktowanych z $2015 \mathrm{roku}^{2}$ (od 4 do $15 \mathrm{pkt}$ ). Pozostałe 12 tytułów to periodyki nowe, ukazujące się na tyle krótko, że nie mogły być poddane ocenie w 2015 roku.

Sprawdzono, które z analizowanych czasopism są indeksowane w międzynarodowych bazach danych. Wzięto pod uwagę te bazy danych, które miały wpływ na zawartość wykazu czasopism punktowanych, czyli Scopus, Web of Science Core Collection i ERIH Plus. Najwięcej periodyków (50) było zarejestrowanych w bazie ERIH plus. W Web of Science Core Collection (Emerging Sources Citation Index) odnaleziono cztery czasopisma: „Alkoholizm i Narkomania”, „E-Mentor”, „Journal of Education Culture and Society”, „The Person and the Challenges”. W Scopusie było indeksowanych pięć kolejnych tytułów: „Baltic Linguistics”, „Images. The International Journal of European Film, Performing Arts and Audiovisual Communication”, „The New Educational Review”, „Qualitative Sociology Review” oraz „Studia Socjologiczne”. W przypadku analizowanych polskich czasopism

2 Kryteria oceny czasopism z 2015 roku były „ostatnimi” nowo opracowanymi, kolejne wykazy były jedynie aktualizowane. Aktualizacja dotyczyła wyłącznie części A wykazu. 
większość została uwzględniona w wykazie czasopism punktowanych w wyniku konkursu „Wsparcie dla czasopism naukowych” - 52 tytuły. Pozostałe zostały umieszczone w wykazie ze względu na ich indeksację w bazach (Web of Science Core Collection lub Scopus - dziewięć tytułów) oraz jako wynik rekomendacji ekspertów na podstawie wskazania z bazy ERIH Plus (13 tytułów).

Pod względem częstotliwości ukazywania się czasopism pedagogicznych najwięcej odnotowano kwartalników (28 czasopism), nieco mniej półroczników (22 czasopisma) i roczników (19 czasopism). Pozostałe cztery periodyki były wydawane z inną częstotliwością.

Wydawcy lub współwydawcy czasopism pedagogicznych to przede wszystkim uczelnie wyższe, instytuty naukowe, fundacje, stowarzyszenia oraz w niewielkim stopniu podmioty komercyjne. Najwięcej czasopism wydaje aktualnie Akademia Pedagogiki Specjalnej im. M. Grzegorzewskiej (sześć tytułów), Uniwersytet im. Adama Mickiewicza (pięć tytułów), Akademia Ignatianum oraz Uniwersytet Pedagogiczny im. Komisji Edukacji Narodowej (po cztery tytuły), Uniwersytet Marii Curie-Skłodowskiej i Uniwersytet Śląski (po trzy tytuły).

Sprawdzając model udostępniania zawartości czasopisma i dostępność pełnych tekstów, w przypadku znacznej większości analizowanych periodyków nie odnotowano trudności z zapoznaniem się z zawartością numerów opublikowanych w 2019 roku. Ponieważ dwa czasopisma nie zamieszczały pełnych tekstów, wykorzystano bazę CEEOL, a w jednym przypadku - z powodu trudności związanych z pobraniem plików ze strony czasopisma - dane pochodzące $\mathrm{z}$ archiwum zgromadzonego w bibliotece cyfrowej. Generalnie osoby chętne do zapoznania się $\mathrm{z}$ treściami opublikowanymi w polskich naukowych czasopismach pedagogicznych nie powinny mieć problemu w dotarciu do nich. Można się zatem spodziewać, że redakcje czasopism wraz z umieszczeniem $\mathrm{w}$ sieci pełnej zawartości opatrzą te teksty stosowną licencją wskazującą na warunki korzystania $\mathrm{z}$ danego dzieła.

Najbardziej znane i rozpowszechnione są licencje Creative Commons (CC), ale redakcja może przygotować własną licencję. Konieczność „upowszechniania artykułów naukowych zamieszczanych w czasopiśmie w trybie otwartego dostępu w Internecie nie później niż w terminie sześciu miesięcy od dnia wydania numeru czasopisma, w sposób bezpłatny i bez technicznych ograniczeń" nakłada na wydawców czasopism, które otrzymały wsparcie w ramach konkursu, Rozporządzenie Ministra Nauki i Szkolnictwa Wyższego z dnia 20 września 2018 roku w sprawie pomocy de minimis $w$ ramach programu "Wsparcie dla czasopism naukowych” (Rozporządzenie..., 2018b). Informacji o stosowanej otwartej licencji nie udało się odnaleźć na stronach 21 czasopism. Być może liczba periodyków, które nie stosują otwartej licencji, jest mniejsza, ale odnalezienie tej informacji na stronach analizowanych periodyków nie zawsze było łatwe, ponieważ są one umieszczane w różnych miejscach (strona główna, plik z tekstem, instrukcja dla autorów, cel i zakres itp.).

Wśród czasopism, w odniesieniu do których zidentyfikowano licencje, było 21 periodyków publikujących na licencjach wolnych (w tym: CC-BY - 14 tytułów 
i CC-BY-SA - siedem tytułów), a 31 udostępniało swoje treści na pozostałych otwartych licencjach (w tym CC-BY-NC-ND - 16 tytułów, CC-BY-ND - 11 tytułów, CC-BY-NC - trzy tytuły i CC-BY-NC-SA - jeden tytuł).

\section{Wyniki badań}

\section{Język publikacji}

Ogólnie, we wszystkich analizowanych czasopismach $(N=73)$ artykuły w języku angielskim stanowiły mniejszość (943 spośród 2407 analizowanych tekstów, 39 proc.). Z jednej strony niewielki udział artykułów angielskojęzycznych może stanowić o pewnym zamknięciu (Shi, Wenyu, Jinwei, 2005), z drugiej zaś niektórzy opowiadają się za wielojęzycznym i wielokulturowym modelem czasopism jako alternatywy dla hegemonii międzynarodowych czasopism angielskojęzycznych (Espinet, Izquierdo, Garcia-Pujol 2015). Spośród 73 analizowanych periodyków, w 17 czasopismach $(23,29$ proc.) w 2019 roku wszystkie artykuły były publikowane w języku angielskim. W siedmiu innych periodykach pełne teksty w języku angielskim stanowiły większość (ok. 60-70 proc. tekstów w języku angielskim) lub zdecydowaną większość artykułów (ok. 90 proc. tekstów w języku angielskim). W czterech przypadkach pełne teksty w języku angielskim stanowiły blisko połowę artykułów opublikowanych w badanym roku. Artykuły w języku angielskim w mniejszości (poniżej 50 proc.) były publikowane w 40 czasopismach. Przy czym rozbieżności w tej grupie były duże, od zaledwie jednego artykułu $\mathrm{w}$ języku angielskim na $60 \mathrm{w}$ danym periodyku, po siedem artykułów w języku angielskim na 17 opublikowanych w innym czasopiśmie. Natomiast na łamach pięciu periodyków w 2019 roku pełne teksty artykułów opublikowano wyłącznie w języku polskim. Autorzy artykułów publikowali w czasopismach także w ośmiu innych językach niż polski i angielski. W 12 czasopismach pojawiały się także prace po czesku, francusku, hiszpańsku, niemiecku, rosyjsku, ukraińsku, serbsku lub włosku. Jednakże publikowanie w innych językach niż polski i angielski było zjawiskiem marginalnym. Warto też wspomnieć o czterech czasopismach, na łamach których artykuły były publikowane w dwóch wersjach językowych: polskiej i angielskiej („Studia Paedagogica Ignatiana”, „Edukacja Elementarna w Teorii i Praktyce”, „Resocjalizacja Polska = Polish Journal of Social Rehabilitation” oraz "Siedleckie Zeszyty Komeniologiczne. Seria Pedagogika”). Były także pojedyncze artykuły w wersjach językowych: polskiej i włoskiej („Studia Paedagogica Ignatiana”) oraz ukraińskiej i angielskiej oraz serbskiej i angielskiej („Siedleckie Zeszyty Komeniologiczne. Seria Pedagogika"). 


\section{Recenzenci}

Badanie zagadnień związanych z umiędzynarodowieniem czasopisma obejmuje także analizę afiliacji recenzentów, jednakże w odniesieniu do polskich periodyków z pedagogiki zrezygnowano z przeprowadzania takiej analizy ze względu na niereprezentatywność próby. Kompletne informacje dotyczące recenzentów, czyli wskazanie osób, które recenzowały publikacje z 2019 roku, wraz z ich afiliacjami (a przynajmniej instytucjami), udało się odnaleźć jedynie na stronach internetowych $22 \mathrm{z} 73$ czasopism. Redakcje pozostałych periodyków stosowały różne praktyki w tym zakresie. Najczęściej pojawiała się wspólna lista recenzentów bez podziału na poszczególne lata; czasem brakowało wykazu za 2019 rok. Na niektórych stronach w ogóle nie było wskazanych recenzentów lub nie podano ich afiliacji.

\section{Redaktorzy i rady naukowe czasopism}

Sposób prezentacji redaktorów i rad naukowych na stronach internetowych czasopism Redakcje analizowanych czasopism w różny sposób informowały na stronach internetowych o redaktorach i radach naukowych. Informacje te były zamieszczane na jednej podstronie ( 52 proc. czasopism) lub na dwóch podstronach (44 proc. czasopism, gdzie na jednej podstronie był zaprezentowany zespół redakcyjny, na drugiej rada naukowa). W znikomej liczbie przypadków redaktorzy i rady były prezentowane nawet na trzech różnych podstronach (cztery proc. czasopism). Dane szczegółowe dotyczące kwerendy przeprowadzonej na stronach internetowych analizowanych czasopism przedstawiono w tabeli 1 . Również na zdecydowanej większości stron internetowych wskazano funkcje, jakie pełnią poszczególne osoby w czasopiśmie. W przypadku co drugiej strony internetowej zabrakło wskazania instytucji przy wszystkich osobach zaangażowanych w prace redakcyjne lub będące członkami rad naukowych. Niesatysfakcjonujący wynik otrzymano również w przypadku podawania nazwy kraju przy redaktorach i członkach rad naukowych. Na większości analizowanych stron w ogóle nie zamieszczono danych dotyczących kraju lub podano je wybiórczo przy wybranych osobach. Na zaledwie jednej na 10 analizowanych stron internetowych szerzej zaprezentowano sylwetkę redaktora naczelnego czasopisma. Wyniki te są zbieżne $\mathrm{z}$ analizą polskich czasopism biorących udział w konkursie „Wsparcie dla czasopism naukowym” (Drabek, BemkeŚwitilnik 2020a). 
Tabela 1. Sposób prezentacji danych dotyczących redaktorów i rad naukowych polskich czasopism pedagogicznych na stronach internetowych czasopism $(N=73)$

\begin{tabular}{|l|c|c|}
\hline \multicolumn{1}{|c|}{ Kryterium } & Tak & Nie \\
\hline $\begin{array}{l}\text { Przypisanie funkcji wszystkim osobom wcho- } \\
\text { dzącym w skład redakcji i rad naukowych - mają } \\
\text { przypisaną funkcję }\end{array}$ & 67 (91,78 proc.) & $6(8,22$ proc.) \\
\hline $\begin{array}{l}\text { Wskazanie przy każdym redaktorze i członku rady } \\
\text { naukowej nazwy instytucji }\end{array}$ & 33 (45,21 proc.) & 40 (54,79 proc.) \\
\hline $\begin{array}{l}\text { Wskazanie nazwy kraju przy każdym redaktorze } \\
\text { i członku rady naukowej }\end{array}$ & 24 (32,88 proc.) & 49 (67,12 proc.) \\
\hline $\begin{array}{l}\text { Zamieszczenie odnośnika do profesjonalnej } \\
\text { strony prezentującej osobę Redaktora Naczelnego } \\
\text { (ResearchGate/strona osobista/strona instytucjo- } \\
\text { nalna/CV) lub numer ORCID lub krótkiej notki } \\
\text { prezentującej sylwetkę naukową. }\end{array}$ & 7 (9,59 proc.) & 66 (90,41 proc.) \\
\hline $\begin{array}{l}\text { Zaprezentowanie informacji o redaktorach i radzie } \\
\text { naukowej na podstronie/podstronach przeznaczo- } \\
\text { nej tylko do zamieszczenia tej informacji }\end{array}$ & 71 (97,3 proc.) & 2 (2,74 proc.) \\
\hline
\end{tabular}

W nielicznych przypadkach informacje zaprezentowane na stronach internetowych były niekompletne (brak spisu redaktorów głównych, brak spisu członków rady naukowej). Pojedyncze aberracje zanotowano również w następujących przypadkach: wskazanie pełnej afiliacji na stronie polskojęzycznej, którą pominięto na stronie angielskojęzycznej lub zamiast pełnych nazw krajów wskazanie kodów (np. PL, USA, TW).

\section{Stosowana terminologia $w$ nazewnictwie redaktorów $i$ rad naukowych}

Ze względu na dużą różnorodność stosowanej terminologii w języku angielskim, dotyczącej nazewnictwa funkcji poszczególnych redaktorów i rad naukowych, trudno było zorientować się w strukturze organizacyjnej czasopism. Podobne zjawisko odnotowano już w przypadku polskich czasopism (Drabek, Bemke-Świtilnik 2020a) i czasopism chorwackich (Utrobičić, Šimić, Malički et al. 2012). Ponadto w stosowanym nazewnictwie pojawiały się błędy ortograficzne. Charakterystyczne było nazywanie zespołu redakcyjnego określeniem editorial board, a rady naukowej scientific board lub scientific council. Podczas gdy na międzynarodowym rynku wydawniczym zespół redakcyjny jest powszechnie określany terminem editorial team lub editorial office, a rada naukowa to zazwyczaj editorial board. W kilkunastu przypadkach zabrakło spójności zawartości strony internetowej czasopisma z jej wersją językową, tzn. na stronach angielskojęzycznych była umieszczona terminologia w języku polskim. 


\section{Umiędzynarodowienie}

Do przeprowadzenia analizy umiędzynarodowienia redaktorów i członków rad naukowych niezbędne było podanie danych dotyczących afiliacji tych osób, umieszczanych na stronach internetowych czasopism. Praktyki stosowane przez redakcje w tym zakresie były różne. Na nieco ponad połowie stron internetowych analizowanych czasopism ( 39 czasopism - 53 proc.) nie wskazano afiliacji wybranych lub wszystkich członków zespołu redakcyjnego i rad naukowych. Czasopisma, w przypadku których nie odnotowano żadnych brakujących danych lub ich niewielki odsetek (< 10 proc.), stanowiły większość i one zostały uznane za reprezentatywne do analizy umiędzynarodowienia redaktorów i członków rad naukowych $(N=45)$. Łączna liczba redaktorów i członków rad naukowych z uzupełnioną afiliacją dla tej próby wyniosła 1353. Średnia liczba redaktorów i członków rad naukowych dla tych czasopism wyniosła $M=25,34$, przy odchyleniu standardowym $S D=15,858$. Największą liczbę - 106 redaktorów i członków rady naukowej odnotowano dla „Qualitative Sociology Review”. Należy jednocześnie podkreślić, że na stronie internetowej tego czasopisma nie pominięto afiliacji żadnej z tych osób. Średnia liczba redaktorów i członków rad naukowych spoza Polski wyniosła $M=13,16$, przy odchyleniu standardowym $S D=13,150$. Redakcje wszystkich czasopism $(N=45)$ współpracowały z ekspertami spoza Polski, chociaż dominowali eksperci afiliowani w Polsce (rysunek 1).

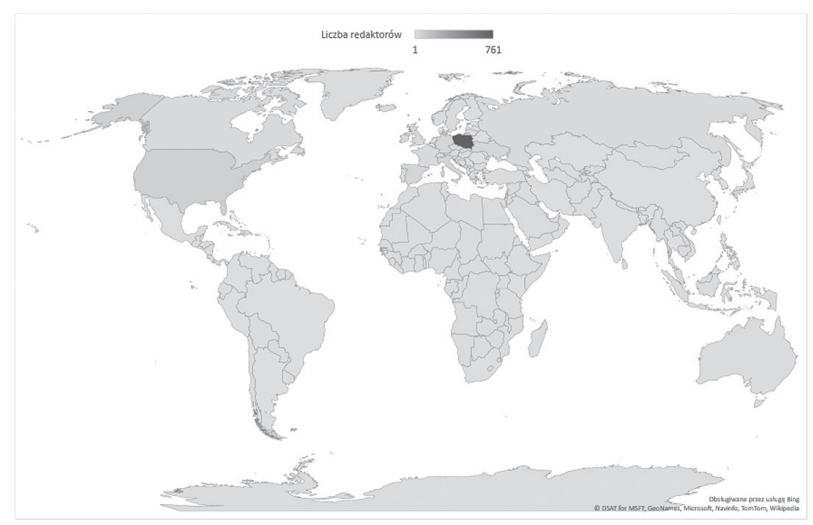

Rysunek 1. Mapa świata ze wskazanymi krajami afiliacji redaktorów polskich czasopism pedagogicznych $(N=45)$

Liczba redaktorów i członków rad naukowych spoza Polski wyniosła 592 (44 proc.). Odsetek redaktorów i członków rad naukowych spoza Polski dla analizowanych czasopism wyniósł średnio $M=39,1$, przy odchyleniu standardowym $S D=14,250$. Największy odsetek redaktorów i członków rad naukowych spoza Polski odnotowano dla „Qualitative Sociology Review” (82,08). W przypadku ośmiu czasopism eksperci spoza Polski w roli redaktorów i członków rad naukowych stanowili większość: „Kwartalnik Pedagogiczny” (61,70 proc.), „Journal of Education 
Culture and Society” (61,54 proc.), „International Journal of Research in E-learning” (61,11 proc.), „Eastern European Journal of Transnational Relations” (6o,71 proc.), "Annales Universitatis Paedagogicae Cracoviensis. Studia ad Didacticam Biologiae Pertinentia” (6o proc.), „Multidisciplinary Journal of School Education” (56,82 proc.), „Paedagogia Christiana” (52,38 proc.), „Ars Inter Culturas” (51,72 proc.). Dla pozostałych 36 czasopism odsetek redaktorów i członków rad naukowych nie przekroczył 50 proc.. Odnotowano niewielką liczbę ekspertów spoza Europy w roli redaktorów i rad naukowych polskich czasopism pedagogicznych (150 osób, 11 proc. wszystkich redaktorów i członków rad naukowych). Spośród analizowanych czasopism eksperci spoza Europy, zaangażowani jako redaktorzy i członkowie rad naukowych, stanowili mniejszość (36 czasopism) lub takiej współpracy w ogóle nie było (dziewięć czasopism). Odsetek tych osób w ogólnej liczbie redaktorów i członków rad naukowych dla wszystkich czasopism stanowił średnio $M=8,44$, przy odchyleniu standardowym $S D=8,676$. Najwyższym odsetkiem redaktorów i członków rady naukowej spoza Europy $(48,11)$ charakteryzowało się czasopismo "Qualitative Sociology Review”. Średnia liczba krajów, w których byli afiliowani redaktorzy i członkowie rad naukowych wyniosła dla wszystkich czasopism $M=8,42$, przy odchyleniu standardowym $S D=4,063$. Największą liczbę krajów (21) odnotowano dla dwóch czasopism "Qualitative Sociology Review" i „Journal of Education Culture and Society". Liczba regionów, w których były zlokalizowane kraje ekspertów w roli redaktorów i członków rad naukowych wahała się od jednego (dziewięć czasopism) do pięciu (trzy czasopisma - „Qualitative Sociology Review”, „Journal of Education Culture and Society” i „Studia Ełckie”). Jednak największą grupę czasopism stanowiły takie, które w składzie redaktorów i członków rad naukowych miały osoby afiliowane w krajach zlokalizowanych w dwóch regionach (21 czasopism - 47 proc.). Zaobserwowano liniową zależność $(r$-Pearson = 0,845) między udziałem redaktorów i członków rad naukowych spoza Polski w ogólnej liczbie redaktorów i członków rad naukowych a liczbą krajów reprezentowanych przez redaktorów i członków rad naukowych (rysunek 2).

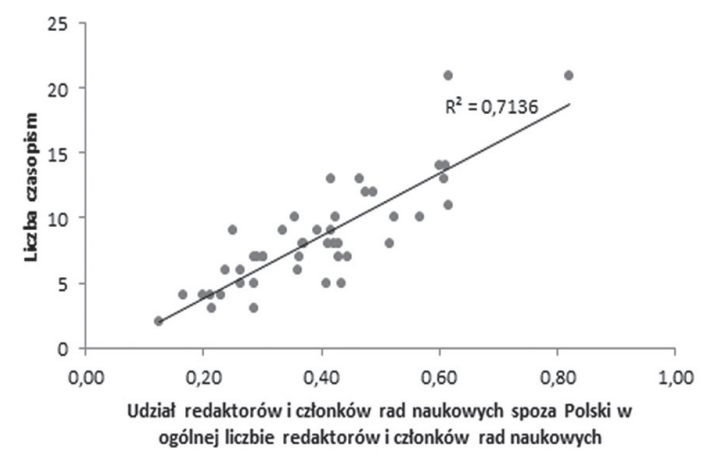

Rysunek 2. Rozkład liczby czasopism według udziału redaktorów i członków rad naukowych spoza Polski $(N=45)$ 


\begin{abstract}
Autorzy
W analizie umiędzynarodowienia autorów podstawą były dane dotyczące afiliacji autorów umieszczone w plikach .pdf artykułów. W zdecydowanej większości czasopism ( 56 czasopism - 77 proc.) podano afiliację wszystkich autorów. Należy podkreślić, że stosunkowo częste było nieuwzględnianie krajów w afiliacjach autorów. Zdarzało się również, że w afiliacji podawano kraj wyłącznie w przypadku autorów spoza Polski, a w przypadku krajowych publikacji nazwa kraju była już pomijana. Tam, gdzie odnotowano odstępstwa (17 czasopism - 23 proc.), odsetek autorów bez afiliacji (brak instytucji i kraju) był niewielki ( $<10$ proc.). Stąd wszystkie czasopisma uznano za reprezentatywne do dalszej analizy. W zbiorze analizowanych czasopism $(N=73)$ dominowali autorzy z Polski (8o proc.), co jest widoczne na rysunku 3.
\end{abstract}

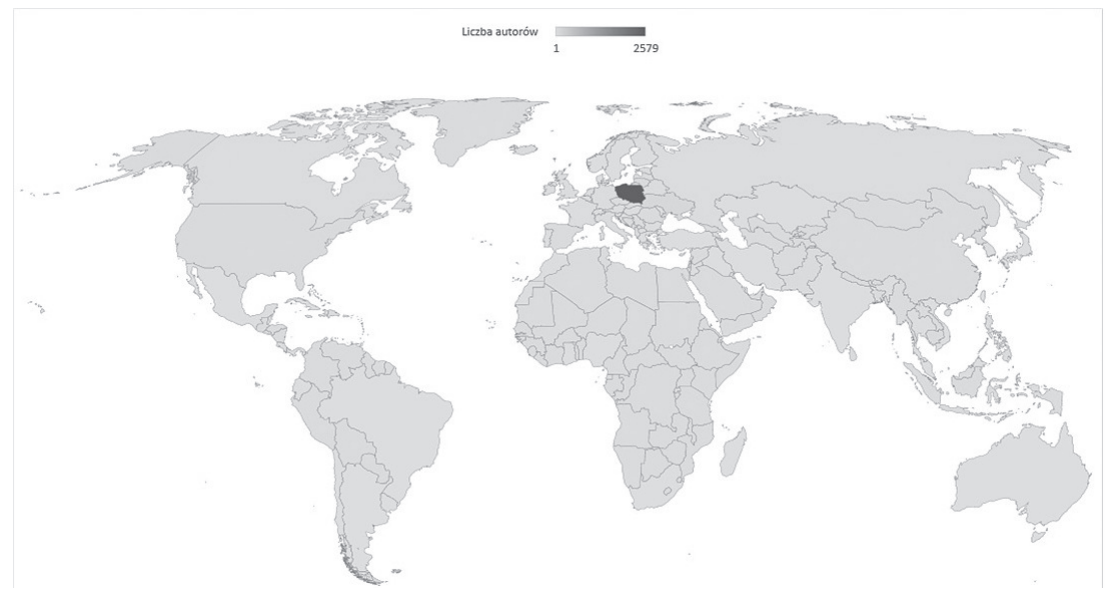

Rysunek 3. Mapa świata ze wskazanymi krajami afiliacji autorów publikujących w polskich czasopismach pedagogicznych $(N=73)$

Uzyskany wynik jest zbieżny $\mathrm{z}$ badaniem dotyczącym brazylijskich czasopism pedagogicznych indeksowanych w bazie Scopus, w przypadku których stwierdzono 79,35 proc. autorów z Brazylii (Madrid, Martín 2017). Podobnym przypadkiem były też trzy australijskie czasopisma pedagogiczne indeksowane w Web of Science Core Collection, których autorzy w 75 proc. byli afiliowani w Australii (Mertova, Ertl, Zierer 2019, s. 224). W analizowanych polskich czasopismach pedagogicznych odsetek autorów spoza Polski wyniósł średnio $M=20,07$, przy odchyleniu standardowym $S D=22,318$. Biorąc pod uwagę dane zadeklarowane przez przedstawicieli redakcji polskich czasopism pedagogicznych, w ramach ewaluacji prowadzonej przez Ministerstwo Nauki i Szkolnictwa Wyższego, nastąpił wzrost odsetka autorów zagranicznych w analizowanych czasopismach (por. Rozkosz 2017, s. 161). W przypadku 14 czasopism (19 proc.) w analizowanym 2019 roku nie opublikowano 
żadnego artykułu, którego autorem był naukowiec spoza Polski. W kilkunastu przypadkach (17 czasopism - 23 proc.) odsetek autorów spoza Polski wyniósł $\leq 10$ proc., natomiast w co drugim spośród 73 czasopism liczba autorów spoza Polski wyniosła $\leq 50$ proc.. W pięciu przypadkach liczba autorów spoza Polski stanowiła zdecydowaną większość lub większość: „Multidisciplinary Journal of School Education” (93 proc.), „The New Educational Review” (80 proc.), „Qualitative Sociology Review” (7o proc.), „International Journal of Pedagogy, Innovation and New Technologies” (6o proc.), „Studia Poradoznawcze = Journal of Counsellogy” (58 proc.). Dla jednego periodyku („Baltic Linguistics”) uzyskano wartość 100 proc. autorów spoza Polski. Jednak wynik ten wymaga osobnego komentarza. Wielu spośród autorów, którzy opublikowali swoje artykuły na łamach tego czasopisma, wskazało dwie afiliacje. $W$ ramach niniejszego badania, w przyjętym sposobie postępowania $\mathrm{z}$ autorami z przypisaną więcej niż jedną afiliacją, uwzględniono tylko pierwszą afiliację. W plikach .pdf artykułów opublikowanych w „Baltic Linguistics" żadna z pierwszych afiliacji nie odnosiła się do Polski. Zaobserwowano liniową zależność $(r$-Pearson $=0,455)$ między udziałem autorów spoza Polski w ogólnej liczbie autorów a liczbą krajów reprezentowanych przez tych autorów. Średnia liczba krajów, które reprezentowali autorzy artykułów opublikowanych na łamach analizowanych czasopism wyniosła $M=4,21$, przy odchyleniu standardowym $S D=3,969$. Największą grupę czasopism stanowiły periodyki, których autorzy byli afiliowani w jednym kraju - w Polsce (14 czasopism - 19 proc.), następnie dwóch krajów (13 czasopism - 18 proc.), trzech krajów (12 czasopism - 16 proc.), pięciu krajów (10 czasopism - 14 proc.) i czterech krajów (dziewięć czasopism - 12 proc.). Największą liczbą krajów było 28 odnotowaną dla czasopisma „The New Educational Review". Dla porównania, w badaniu pięciu wiodących czasopism pedagogicznych indeksowanych w Web of Science Core Collection w latach 2000-2004 liczba krajów reprezentowanych przez autorów wyniosła 18 (Cheung 2009). Średnia liczba regionów reprezentowanych przez autorów wyniosła $M=1,66$ przy odchyleniu standardowym $S D=0,815$. Dominującym regionem była Europa, w co drugim czasopiśmie autorzy byli afiliowani wyłącznie w krajach europejskich (38 czasopism - 52 proc.). Kolejną grupę stanowiły czasopisma, których autorzy byli afiliowani w krajach zlokalizowanych w dwóch różnych regionach (25 czasopism - 34 proc.). $\mathrm{W}$ czasopismach tych najczęściej reprezentowanym drugim regionem (po Europie) była Ameryka Północna, potem Azja i Ameryka Południowa (kolejno 13 czasopism, dziewięć i trzy czasopisma). Redakcje niewielkiego odsetka czasopism zgromadziły na łamach swoich periodyków autorów pochodzących z trzech różnych regionów (siedem czasopism - 10 proc.) i czterech regionów (trzy czasopisma cztery proc.). Na liście czasopism, których autorzy byli afiliowani w największej liczbie regionów świata, znalazły się następujące tytuły: „The New Educational Review” (regiony: Europa, Ameryka Północna, Azja, Afryka), „Qualitative Sociology Review” (regiony: Europa, Ameryka Północna, Azja, Afryka), „International Journal of Pedagogy, Innovation and New Technologies" (regiony: Europa, Ameryka 
Północna, Ameryka Południowa, Afryka). Rozkład liczby czasopism według liczby krajów i regionów przedstawiono na rysunku 4.

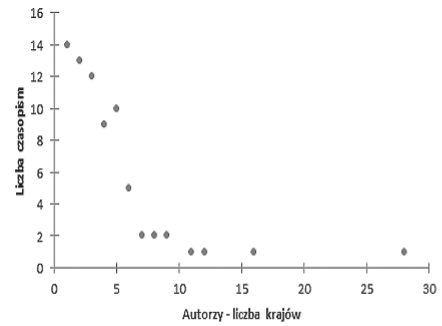

a)

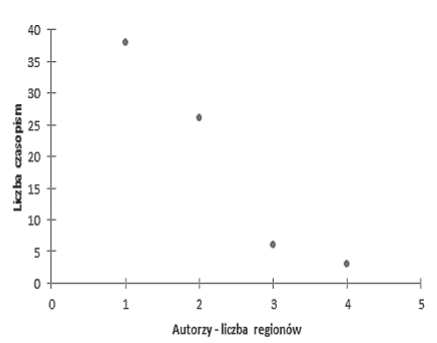

Rysunek 4. Rozkład liczby czasopism $(N=73)$ według: a) liczby krajów

reprezentowanych przez autorów, b) liczby regionów reprezentowanych przez autorów

\section{Dyskusja i podsumowanie}

Analiza przeprowadzona w ramach niniejszego artykułu ujawniła niewielki odsetek periodyków wyłącznie angielskojęzycznych (17 czasopism, 23 proc.). Chociaż liczba krajów, które reprezentowali zarówno redaktorzy i członkowie rad naukowych, jak i autorzy, była wysoka, to jednak w jednym i drugim przypadku dominowali eksperci z Polski. Pod względem umiędzynarodowienia zespołu redakcyjnego i rad naukowych wysokim odsetkiem zagranicznych ekspertów wyróżniło się dziewięć czasopism:

- „Qualitative Sociology Review”,

- „Kwartalnik Pedagogiczny”,

- „Journal of Education Culture and Society”,

- „International Journal of Research in E-learning”,

- „Eastern European Journal of Transnational Relations”,

- „Annales Universitatis Paedagogicae Cracoviensis. Studia ad Didacticam Biologiae Pertinentia",

- „Multidisciplinary Journal of School Education”,

- „Paedagogia Christiana”,

- „Ars Inter Culturas”.

Mniejsza grupa, pięciu czasopism, została wyróżniona pod względem wysokiego odsetka autorów zagranicznych:

- „Multidisciplinary Journal of School Education”,

- "The New Educational Review”,

- „Qualitative Sociology Review”,

- „International Journal of Pedagogy, Innovation and New Technologies”,

- „Studia Poradoznawcze = Journal of Counsellogy”. 
Trzy z wymienionych czasopism są już indeksowane w Web of Science Core Collection lub Scopus („Qualitative Sociology Review”, „Journal of Education Culture and Society”, „The New Educational Review”). Pozostałych 10 periodyków nie jest indeksowanych w tych bazach. Niewielka liczba periodyków wyróżnionych w niniejszym badaniu skłania do dyskusji nad kierunkami rozwoju polskich czasopism pedagogicznych. Należy rozpatrywać dwa kierunki rozwoju polskich czasopism pedagogicznych: międzynarodowy lub krajowy. Tak rozbieżne możliwości mogą rodzić pewien dylemat, stąd uzasadniona wydaje się potrzeba szerszej dyskusji środowiska nad przyszłością tych czasopism. Takie debaty są prowadzone w innych krajach. Na przykład redaktor hiszpańskiego czasopisma „Revista Española de Pedagogía” zainicjował w 2018 roku tzw. okrągły stół, do którego zaprosił redaktorów innych czasopism pedagogicznych (nie tylko hiszpańskich), co zaowocowało dyskusją na różne tematy, m.in. współczesnych badań z zakresu pedagogiki i wyzwań, jakie stoją przed redaktorami tych czasopism (Ibáñez-Martín 2018). Z kolei Trung Tran i in. (2019) wybrali 13 czasopism pedagogicznych spośród wszystkich 387 czasopism wietnamskich uznawanych w awansach profesorskich w tym kraju i na podstawie prostej analizy, z wykorzystaniem minimalnych wymagań stawianych czasopismom zgłaszanym do bazy Scopus, sformułowali długoterminowe cele, jakie powinni przed sobą postawić redaktorzy tych czasopism. Przyjęcie kierunku umiędzynarodowienia (angielskojęzyczność, międzynarodowe grono redaktorów i członków rad naukowych, autorów i recenzentów) jest związane, jak pisze José Luis Hernández Huerta i in. (2019, s. 223), z poświęceniem pewnej części lokalnej społeczności, która może nie podążyć za tym kierunkiem rozwoju. Kierunek krajowy rozwoju czasopism pedagogicznych może być szczególnie ważny dla lokalnych społeczności, przede wszystkim ze względu na brak bariery językowej i związanej z tym swobodnej komunikacji.

Sugerowaną potrzebę dyskusji środowiska na temat przyszłości polskich czasopism pedagogicznych i ich strategii rozwoju mogą wspierać rekomendacje powstałe w związku z zaistniałymi trudnościami i poczynionymi obserwacjami w trakcie gromadzenia danych do niniejszego badania. Mają one charakter formalny i częściowo pokrywają się z wytycznymi sformułowanymi w ramach innego badania (Drabek, Bemke-Świtilnik 2020a). Angielskojęzyczna terminologia w zakresie nazewnictwa zespołów redakcyjnych i rad naukowych wymaga ujednolicenia i dostosowania do praktyk w tym zakresie, stosowanych przez wydawców i redaktorów międzynarodowych czasopism. Kolejnym obszarem doskonalenia jest konsekwentne wypełnianie stron internetowych czasopism w wersji angielskojęzycznej tekstem $\mathrm{w}$ języku tożsamym z tą wersją. Jak wykazały badania ankietowe przeprowadzone wśród autorów wiodących czasopism pedagogicznych indeksowanych w Web of Science Core Collection, znajomość kompetencji zawodowych, zainteresowań intelektualnych i cech osobistych redaktora, była uwzględniania przez autorów przy wyborze czasopisma do publikacji artykułu (Cheung 2008). Stąd można przypuszczać, że umieszczenie na stronach internetowych not o redaktorach i członkach 
rad naukowych czy odnośników do profesjonalnych stron prezentujących dorobek tych osób może wspomagać decyzję o publikowaniu w danym czasopiśmie. Istotne jest również wskazywanie na stronach internetowych czasopism pełnej afiliacji (pełna nazwa instytucji i kraju) wszystkich redaktorów i członków rad naukowych. Z kolei w przypadku afiliacji autorów należy podawać pełną afiliację wszystkich autorów, również tych afiliowanych w polskich instytucjach. Należy podkreślić, że rekomendowane praktyki są niezależne od przyjętego kierunku rozwoju czasopisma, międzynarodowego czy krajowego.

\section{Bibliografia}

Cheung C.K. (2008). Audience matters: A study of how authors select educational journals. „The Asia-Pacific Education Researcher”, nr 2, s. 191-201.

Cheung C.K. (2009). Possible Biases in Educational Journals: A Retrospective Study of Five Leading Journals. „Asia-Pacific Education Researcher”, nr 1, 129-138.

Drabek A., Bemke-Świtilnik M. (2020a). Polskie czasopisma naukowe w świetle wybranych elementów oceny stosowanych $w$ międzynarodowych bazach danych. W: Biblioteki uczelniane wobec środowiska akademickiego. Nowe obszary działania. Materiały Jubileuszowej Konferencji Biblioteki Głównej AGH z okazji obchodów 10o-lecia Akademii Górniczo-Hutniczej im. Stanisława Staszica, Kraków 12-13 września 2019 r. Podrazik A., Stanek-Kapcia J., Urbaniec M. (red.). Kraków: Wydawnictwo AGH, s. 107-132.

Drabek A, Bemke-Świtilnik M. (202ob). O wykazach, punktozie i polskich czasopismach humanistycznych. „Forum Akademickie”, nr 11, s. 24-27.

Espinet M., Izquierdo M., Garcia-Pujol C. (2015). Can a Spanish science education journal become international? The case of Enseñanza de las Ciencias. „Cultural Studies of Science Education", nr 4, s. 1017-1031.

Fradkin C. (2017). The internationalization of psychology journals in Brazil: A bibliometric examination based on four indices. „Paidéia (Ribeirão Preto)”, nr 66, s. $7-15$.

Huerta J.L. H., Rico A.P., Blanco C.S. (2019). Global territory and the international map of history of education journals. „International Journal for the Historiography of Education", nr 2, s. 206-226.

Ibáñez-Martín J.A. (2018). Presentation: pedagogical research journals today. „Revista Española de Pedagogía”, nr 271, s. 409-412.

Komunikat Ministra Nauki i Szkolnictwa Wyższego $z$ dnia 18 grudnia 2019 roku $w$ sprawie wykazu czasopism naukowych i recenzowanych materiałów $z$ konferencji międzynarodowych. Dostępny na: https://www.bip.nauka.gov.pl/inne2/ komunikat-ministra-nauki-i-szkolnictwa-wyzszego-z-dnia-18-grudnia-2019-r-w-sprawie-wykazu-czasopism-naukowych-i-recenzowanych-materialow-z-konferencji-miedzynarodowych.html (dostęp 6.12.2020). 
Komunikat Ministra Edukacji i Nauki $z$ dnia 9 lutego 2021 roku w sprawie wykazu czasopism naukowych i materiałów z konferencji międzynarodowych. Dostępny na: https://www.gov.pl/web/edukacja-i-nauka/nowy-rozszerzony-wykaz-czasopism-naukowych-i-recenzowanych-materialow-z-konferencji-miedzynarodowych (dostęp 24.03.2021).

Komunikat Ministra Edukacji i Nauki z dnia 18 lutego 2021 roku o zmianie i sprostowaniu komunikatu w sprawie wykazu czasopism naukowych i recenzowanych materiałów z konferencji międzynarodowych. Dostępny na: https://www.gov.pl/ web/edukacja-i-nauka/nowy-rozszerzony-wykaz-czasopism-naukowych-i-recenzowanych-materialow-z-konferencji-miedzynarodowych (dostęp 24.03.2021).

König C.J. (2019). How much is research in the top journals of industrial/organizational psychology dominated by authors from the US? „Scientometrics”, nr 120 (3), s. $1147-1161$.

Kowolik P. (1999). Czasopisma pedagogiczne w pracy dyrektora szkoły. „Nauczyciel i Szkoła", nr 2, s. 79-88.

Kulczycki E., Rozkosz E.A., Drabek A. (2019). Internationalization of Polish journals in the social sciences and humanities: Transformative role of the research evaluation system. „Canadian Journal of Sociology”, $\mathrm{nr}$ 1, s. 9-38.

Lopez-Fernandez O., Molina-Azorín J.F. (2011). The use of mixed methods research in interdisciplinary educational journals. „International Journal of Multiple Research Approaches", nr 2, s. 269-283.

Madrid Martín M.J., Jiménez-Fanjul N., León-Mantero C., Maz-Machado A. (2017). Revistas brasileñas de Educación en SCOPUS: un análisis bibliométrico. „Biblios: Journal of Librarianship and Information Science", nr 67, s. 30-41.

Mertova P., Ertl, H., Zierer K. (2019). Education journals: A comparison of publishing patterns in Australian, German and English education journals. „Research in Comparative and International Education", nr 2, s. 215-230.

Pasikowski S. (2018). Ocena transparentności postępowania badawczego. Implikacje dla badań nad dzieciństwem. „Edukacja Elementarna w Teorii i Praktyce”, nr 4 (50), s. 27-39.

Rozkosz E.A. (2017). Polskie czasopisma pedagogiczne $w$ „Wykazach czasopism punktowanych" w latach 2012, 2013 i 2015. W: Komunikacja naukowa w humanistyce. E. Kulczycki (red.). Poznań: Wydawnictwo Naukowe Instytutu Filozofii UAM, s. 153-173.

Rozporzadzenie..., 2018a. Rozporządzenie Ministra Nauki i Szkolnictwa Wyższego $z$ dnia 20 września 2018 roku w sprawie dziedzin nauki i dyscyplin naukowych oraz dyscyplin artystycznych. Dz.U. z 2018 roku, poz. 1818. Dostępny na: http://isap. sejm.gov.pl/isap.nsf/DocDetails.xsp?id=WDU20180001818 (dostęp 10.12.2020).

Rozporządzenie..., 2018b. Rozporządzenie Ministra Nauki i Szkolnictwa Wyższego $z$ dnia 20 września 2018 roku w sprawie pomocy „de minimis" w ramach programu „Wsparcie dla czasopism naukowych”. Dz.U. z 2018 roku, poz. 1832. Dostępny 
na: http://isap.sejm.gov.pl/isap.nsf/DocDetails.xsp?id=WDU20180o01832 (dostęp 10.12.2020).

Shi L., Wenyu W., Jinwei X. (2005). Publication culture of foreign language education journals in China. „TESOL Quarterly”, nr 4, s. 765-776.

Tran T., Nguyen L.T. M., Nghiem T.T., Le H.T. T., Nguyen C.H., La T.P., Nguyen H.T.T. (2019). Compliance of education journals in Vietnam with the minimum criteria to be indexed in the ASEAN Citation Index and Scopus. „Science Editing”, nr 2, s. 142-147.

Utrobičić A., Šimić J., Malički M., Marušić M., Marušić A. (2014). Composition of editorial boards and peer review policies of Croatian journals indexed in Web of Science and Scopus. „European Science Editing”, nr 2, s. 31-33.

Yalcin S., Yavuz H.C., Dibek M.İ. (2015). Content Analysis of Papers Published in Educational Journals with High Impact Factors. „Egitim ve Bilim”, nr 182, s. 1-28.

\title{
INTERNATIONAL OR NATIONAL? A BIBLIOMETRIC ANALYSIS OF POLISH PEDAGOGICAL JOURNALS
}

\begin{abstract}
The article presents the analysis of the internationalization of 73 Polish pedagogical journals. The analyzed parameters of internationalization were related to the language of publication, the affiliation of editors and members of editorial boards, and contributing authors. The parameters concerning reviewers were omitted due to different practices in informing about experts engaged in the peer review process; therefore the sample of journals was not representative for analysis. The data was gathered from the journals' websites and articles published in 2019. Results were related to the small number of journals with high values of parameters of internationalization, namely 16 journals were English-only (22\%), nine journals had a high percentage of editors and editorial board members outside Poland (12\%), five journals had a high percentage of authors outside Poland ( $7 \%$ ). The collaboration with editors and editorial board members and authors outside Europe was low. The possible national and international directions for the development of Polish pedagogical journals were proposed. The formal recommendations for editors and publishers of these journals were formulated.
\end{abstract}

Keywords: polish education journals; internationalization; editors; editorial board members; authors; publication language. 


\section{Załącznik 1. Wykaz polskich czasopism pedagogicznych wybranych do analizy}

\begin{tabular}{|c|c|c|c|}
\hline Tytuł & ISSN & e-ISSN & $\begin{array}{l}\text { Dyscypliny w wy- } \\
\text { kazie czasopism } \\
\text { punktowanych }\end{array}$ \\
\hline $\begin{array}{l}\text { "Alkoholizm i Narkomania” = „Alcoholism } \\
\text { and Drug Addiction” }\end{array}$ & $0867-4361$ & $1689-3530$ & $\begin{array}{l}\text { P, NZ, NS, NF, NP, } \\
\text { NM }\end{array}$ \\
\hline $\begin{array}{l}\text { "Annales Universitatis Mariae Curie- } \\
\text { Skłodowska. Sectio J. Paedagogia-Ps" }\end{array}$ & $0867-2040$ & $2449-8521$ & P, Ps \\
\hline $\begin{array}{l}\text { "Annales Universitatis Mariae Curie- } \\
\text { Skłodowska. Sectio N. Educatio Nova" }\end{array}$ & $2451-0491$ & $2543-9340$ & $\mathrm{~J}, \mathrm{P}, \mathrm{L}, \mathrm{NSz}, \mathrm{Ps}$ \\
\hline $\begin{array}{l}\text { "Annales Universitatis Paedagogicae } \\
\text { Cracoviensis. Studia ad Didacticam Biologiae } \\
\text { Pertinentia” }\end{array}$ & $2083-7267$ & $2450-3487$ & $\mathrm{P}$ \\
\hline $\begin{array}{l}\text { "Annales Universitatis Paedagogicae } \\
\text { Cracoviensis. Studia ad Didacticam } \\
\text { Litterarum Polonarum et Linguae Polonae" }\end{array}$ & 2082-0909 & $2450-5013$ & J, P, L, NK \\
\hline "Ars Inter Culturas" & $2083-1226$ & & $\mathrm{P}, \mathrm{L}, \mathrm{NKR}, \mathrm{NSz}$ \\
\hline „Baltic Linguistics” & $2081-7533$ & & $\mathrm{~J}, \mathrm{P}, \mathrm{L}, \mathrm{NK}$ \\
\hline „Biografistyka Pedagogiczna” & $2543-6112$ & 2543-7399 & $\mathrm{P}, \mathrm{NKR}, \mathrm{H}, \mathrm{NS}$ \\
\hline „Colloquium” & $2081-3813$ & $2658-0365$ & P, Ps, NPA, NB \\
\hline "Człowiek Niepełnosprawność Społeczeństwo” & $1734-5537$ & & $\mathrm{P}$ \\
\hline „Dyskursy Młodych Andragogów” & $2084-2740$ & & $\mathrm{P}$ \\
\hline $\begin{array}{l}\text { "Eastern European Journal of Transnational } \\
\text { Relations” }\end{array}$ & $2544-9214$ & 2544-9737 & P, NPA, EF, NP \\
\hline „Edukacja Dorosłych” & $1230-929 \mathrm{X}$ & & $\mathrm{P}$ \\
\hline „Edukacja Elementarna w Teorii i Praktyce” & $1896-2327$ & $2353-7787$ & $\mathrm{P}, \mathrm{L}, \mathrm{H}, \mathrm{Ps}$ \\
\hline „Edukacja Międzykulturowa” & $2299-4106$ & & $\mathrm{P}, \mathrm{NKR}, \mathrm{NS}, \mathrm{NK}$ \\
\hline „Edukacja Ustawiczna Dorosłych” & $1507-6563$ & & $\mathrm{P}$ \\
\hline „Edukacyjna Analiza Transakcyjna” & $2299-7466$ & $2658-1825$ & $\mathrm{P}$ \\
\hline „E-Mentor” & $1731-6758$ & $1731-7428$ & $\mathrm{P}, \mathrm{A}, \mathrm{EF}, \mathrm{NK}, \mathrm{NZ}$ \\
\hline „Forum Oświatowe” & $0867-0323$ & $2450-3452$ & $\mathrm{P}$ \\
\hline „Forum Pedagogiczne” & $2083-6325$ & $2449-7142$ & $\mathrm{P}$ \\
\hline „Homo Ludens” & $2080-4555$ & & $\begin{array}{l}\text { J, P, L, NKR, NKF, } \\
\text { NS, Ps, NK, I }\end{array}$ \\
\hline „Horyzonty Wychowania” & $1643-9171$ & $2391-9485$ & $\begin{array}{l}\text { J, P, NKR, NS, Ps, F, } \\
\text { NK, NZ, NP }\end{array}$ \\
\hline $\begin{array}{l}\text { „Images. The International Journal of } \\
\text { European Film, Performing Arts and } \\
\text { Audiovisual Communication” }\end{array}$ & $1731-450 X$ & & $\begin{array}{l}\text { P, L, NKR, NSz, } \\
\text { NS, NK }\end{array}$ \\
\hline $\begin{array}{l}\text { „Interdyscyplinarne Konteksty Pedagogiki } \\
\text { Specjalnej” }\end{array}$ & $2300-391 X$ & & $\mathrm{P}$ \\
\hline $\begin{array}{l}\text { "International Journal of Pedagogy, } \\
\text { Innovation and New Technologies" }\end{array}$ & & 2392-0092 & $\mathrm{P}$ \\
\hline
\end{tabular}




\begin{tabular}{|c|c|c|c|}
\hline Tytuł & ISSN & e-ISSN & $\begin{array}{c}\text { Dyscypliny w wy- } \\
\text { kazie czasopism } \\
\text { punktowanych }\end{array}$ \\
\hline $\begin{array}{l}\text { "International Journal of Research in } \\
\text { E-learning” }\end{array}$ & $2451-2583$ & $2543-6155$ & $\mathrm{P}$ \\
\hline "Journal of Education Culture and Society” & $2081-1640$ & & $\begin{array}{l}\text { P, NZ, NS, NPA, } \\
\text { EF, NK, NZ, NB }\end{array}$ \\
\hline „Konteksty Pedagogiczne” & $2300-6471$ & & $\mathrm{P}$ \\
\hline „Kultura - Społeczeństwo - Edukacja” & $2300-0422$ & & $\mathrm{P}, \mathrm{NKR}, \mathrm{NS}, \mathrm{Ps}$ \\
\hline „Kultura i Edukacja” & $1230-266 \mathrm{X}$ & & $\begin{array}{l}\text { P, NKR, NSz, NS, } \\
\text { Ps }\end{array}$ \\
\hline „Kwartalnik Naukowy Fides et Ratio” & & $2082-7067$ & $\begin{array}{l}\text { P, NKR, NSz, NZ, } \\
\text { Ps, F, NT, NM }\end{array}$ \\
\hline „Kwartalnik Pedagogiczny” & $0023-5938$ & & $\mathrm{P}$ \\
\hline „Labor et Educatio" & $2353-4745$ & $2544-0179$ & $\mathrm{P}$ \\
\hline "Logopedia Silesiana” & $2300-5246$ & $2391-4297$ & $\begin{array}{l}\text { J, P, NZ, Ps, NK, } \\
\text { NM }\end{array}$ \\
\hline „Lubelski Rocznik Pedagogiczny” & $0137-6136$ & $2449-8327$ & $\mathrm{P}$ \\
\hline „Media - Kultura - Komunikacja Społeczna” & $1734-3801$ & & $\begin{array}{l}\text { P, NKR, NS, Ps, } \\
\text { NPA, NK }\end{array}$ \\
\hline $\begin{array}{l}\text { "Multidisciplinary Journal of School } \\
\text { Education" }\end{array}$ & $2543-7585$ & $2543-8409$ & $\mathrm{P}$ \\
\hline $\begin{array}{l}\text { „Nauki o Wychowaniu. Studia } \\
\text { Interdyscyplinarne” }\end{array}$ & $2450-4491$ & & $\begin{array}{l}\text { P, NKR, NSz, NS, } \\
\text { Ps, F }\end{array}$ \\
\hline „The New Educational Review” & $1732-6729$ & & $\mathrm{P}, \mathrm{NKF}, \mathrm{NS}$ \\
\hline $\begin{array}{l}\text { „Niepełnosprawność. Dyskursy Pedagogiki } \\
\text { Specjalnej” }\end{array}$ & $2080-9476$ & $2544-0519$ & $\mathrm{P}$ \\
\hline „Paedagogia Christiana” & $1505-6872$ & $2451-1951$ & $\begin{array}{l}\text { P, NKR, NS, Ps, } \\
\text { F, NT }\end{array}$ \\
\hline „The Person and the Challenges” & $2083-8018$ & $2391-6559$ & $\mathrm{P}, \mathrm{NS}, \mathrm{PK}, \mathrm{NT}$ \\
\hline „Podstawy Edukacji” & $2081-2264$ & $2658-2848$ & P, NS, Ps \\
\hline „Polska Myśl Pedagogiczna” & $2450-4572$ & $2450-4564$ & $\mathrm{P}$ \\
\hline „Półrocznik Językoznawczy Tertium” & & $2543-7844$ & J, P, NKR, NK \\
\hline „Praca Socjalna” & $0860-3480$ & & P, NS, NPA \\
\hline „Problemy Opiekuńczo-Wychowawcze” & $0552-2188$ & & $\mathrm{P}$ \\
\hline „Problemy Wczesnej Edukacji” & $1734-1582$ & $2451-2230$ & $\mathrm{P}$ \\
\hline „Przedsiębiorczość - Edukacja” & $2083-3296$ & $2449-9048$ & P, GS, EF, NZ \\
\hline „Przegląd Badań Edukacyjnych” & $1895-4308$ & $2392-1544$ & $\begin{array}{l}\text { P, H, NKF, NZ, NS, } \\
\text { Ps, F, NZ }\end{array}$ \\
\hline „Przegląd Historyczno-Oświatowy” & $0033-2178$ & & $\mathrm{P}$ \\
\hline „Przegląd Pedagogiczny” & $1897-6557$ & & $\mathrm{P}$ \\
\hline "Qualitative Sociology Review” & & $1733-8077$ & P, NKR, NZ, NS \\
\hline $\begin{array}{l}\text { „Resocjalizacja Polska = Polish Journal of } \\
\text { Social Rehabilitation” }\end{array}$ & $2081-3767$ & $2392-2656$ & $\mathrm{P}$ \\
\hline „Rocznik Andragogiczny” & 1429-186X & $2391-7571$ & $\begin{array}{l}\text { P, H, NKF, NS, Ps, } \\
\text { F, NZ }\end{array}$ \\
\hline
\end{tabular}




\begin{tabular}{|c|c|c|c|}
\hline Tytuł & ISSN & e-ISSN & $\begin{array}{c}\text { Dyscypliny w wy- } \\
\text { kazie czasopism } \\
\text { punktowanych }\end{array}$ \\
\hline „Rocznik Lubuski” & $0485-3083$ & & $\mathrm{P}, \mathrm{NS}$ \\
\hline „Rocznik Pedagogiczny” & $0137-9585$ & & $\mathrm{P}$ \\
\hline „Roczniki Nauk Społecznych” & $0137-4176$ & $2544-5812$ & $\begin{array}{l}\text { P, NS, PK, Ps, NK, } \\
\text { NP, NB }\end{array}$ \\
\hline "Roczniki Pedagogiczne” & $2080-850 X$ & $2544-5243$ & $\mathrm{P}$ \\
\hline „Rozprawy Społeczne” & $2081-6081$ & & P, NZ, NS, Ps \\
\hline „Seminare” & $1232-8766$ & $2450-1328$ & $\begin{array}{l}\mathrm{P}, \mathrm{NKR}, \mathrm{H}, \mathrm{NSz} \\
\mathrm{NS}, \mathrm{PK}, \mathrm{Ps}, \mathrm{F}, \mathrm{NT}\end{array}$ \\
\hline $\begin{array}{l}\text { "Siedleckie Zeszyty Komeniologiczne. Seria } \\
\text { Pedagogika" }\end{array}$ & $2450-7245$ & & $\begin{array}{l}\text { J, P, L, H, NSz, NS, } \\
\text { Ps, F, NK, NT }\end{array}$ \\
\hline „Studia Edukacyjne” & $1233-6688$ & & $\mathrm{P}$ \\
\hline „Studia Ełckie” & $1896-6896$ & 2353-1274 & $\begin{array}{l}\text { P, NKR, PK, NK, } \\
\text { NT }\end{array}$ \\
\hline „Studia Paedagogica Ignatiana” & $2450-5358$ & $2450-5366$ & $\mathrm{P}, \mathrm{H}, \mathrm{NS}, \mathrm{F}$ \\
\hline $\begin{array}{l}\text { „Studia Pedagogiczne. Problemy Społeczne, } \\
\text { Edukacyjne i Artystyczne” }\end{array}$ & 2083-179X & $2449-8971$ & $\mathrm{P}$ \\
\hline $\begin{array}{l}\text { „Studia Przyrodoznawcze = Journal of } \\
\text { Counsellogy” }\end{array}$ & $2299-4971$ & $2450-3444$ & $\mathrm{P}, \mathrm{Ps}$ \\
\hline „Studia Socjologiczne” & oo39-3371 & $2545-2770$ & $\begin{array}{l}\text { P, NKR, NKF, NZ, } \\
\text { NS, NP }\end{array}$ \\
\hline „Studia z Teorii Wychowania” & 2083-0998 & & $\mathrm{P}, \mathrm{NS}$ \\
\hline „Szkoła Specjalna” & O137-818X & & $\mathrm{P}$ \\
\hline „Szkoła, Zawód, Praca” & $2082-6087$ & & $\mathrm{P}$ \\
\hline $\begin{array}{l}\text { „Zeszyty Naukowe Katolickiego Uniwersytetu } \\
\text { Lubelskiego” }\end{array}$ & $0044-4405$ & $2543-9715$ & $\begin{array}{l}\mathrm{P}, \mathrm{NS}, \mathrm{NPA}, \mathrm{NK} \\
\mathrm{NP}, \mathrm{NB}\end{array}$ \\
\hline $\begin{array}{l}\text { „Zeszyty Naukowe Wyższej Szkoły } \\
\text { Humanitas. Pedagogika” }\end{array}$ & $1896-4591$ & & P, Ps \\
\hline
\end{tabular}

\section{Kody dyscyplin}

Nauki społeczne: pedagogika (P), Psychologia (Ps), ekonomia i finanse (EF), geografia społeczno-ekonomiczna i gospodarka przestrzenna (GS), nauki i bezpieczeństwie (NB), nauki o komunikacji społecznej i mediach (NK), nauki o polityce i administracji (NPA), nauki o zarządzaniu i jakości (NZ), nauki prawne (NP), nauki socjologiczne (NS), prawo kanoniczne (PK)

Nauki humanistyczne: językoznawstwo (J), literaturoznawstwo (L), historia $(\mathrm{H})$, nauki o kulturze i religii (NKR), filozofia (F), nauki o sztuce (NSz)

\section{Nauki teologiczne: NT}

Nauki medyczne i nauki o zdrowiu: nauki o zdrowiu (NZ), nauki farmaceutyczne (NF), nauki medyczne (NM), nauki o kulturze fizycznej (NKF)

Nauki inżynieryjno-techniczne: architektura i urbanistyka (A)

Nauki ścisłe i przyrodnicze: informatyka (I) 